\section{Ploidy, Relative Genome Size, and Inheritance of Spotted Foliage in Aucuba Species (Garryaceae)}

\author{
Thomas G. Ranney ${ }^{1,5}$, Tracy H. Thomasson ${ }^{2}$, Kristin Neill' ${ }^{2}$, \\ Nathan P. Lynch ${ }^{3}$, and Mark Weathington ${ }^{4}$ \\ Mountain Crop Improvement Lab, Department of Horticultural Science, \\ Mountain Horticultural Crops Research and Extension Center, North \\ Carolina State University, 455 Research Drive, Mills River, NC 28759- \\ 3423
}

Additional index words. cytotype, DNA content, plant breeding, polyploidy

\begin{abstract}
Aucuba have been cultivated for centuries and are valued as adaptable, broadleaved, evergreen shrubs that also can have attractive, spotted variegations on the foliage. Improved understanding of the cytogenetics and heritability of specific traits, for specific clones and cultivars, can provide basic information to help facilitate the breeding and improvement of aucuba. The objectives of this study were to determine ploidy level and relative genome size of a diverse collection of species and cultivars of aucuba using flow cytometry and cytology and to make additional observations on heritability of spotted leaf variegation. Chromosome counts were $2 n=2 x=16$ for Aucuba chinensis (A. omeiensis), $2 n=4 x=32$ for $A$. japonica 'Rozannie', and $2 n=6 x=48$ for $A$. sp. 'Hosoba'. Relative $2 \mathrm{C}$ genome size for the 57 taxa varied from $13.8 \mathrm{pg}$ for $A$. obcordata to $42.0 \mathrm{pg}$ for $A$. 'Hosoba' and fell within three discrete groups consistent with cytotype. Genome size for diploid taxa ( $A$. chinensis and $A$. obcordata) ranged from 13.8 to $21.0 \mathrm{pg}$, tetraploids (A. himalaica var. oblanceolata, $A$. japonica, and $A$. japonica var. borealis) ranged from 28.8 to $31.2 \mathrm{pg}$, and the first-ever reported hexaploids ( $A$. 'Hosoba' and $A$. sp. - Vietnam) ranged from 40.5 to $42.0 \mathrm{pg}$. Unlike prior reports that indicated inheritance of spotted variegations were extranuclear genes that were maternally inherited, we found that the spotted leaf trait expressed in A. japonica 'Shilpot' appears to be a nuclear gene that is inherited in a quantitative fashion and not strictly maternal. These data provide an enhanced foundation for breeding improved aucuba.
\end{abstract}

Aucuba $(A u c u b a)$ is a relatively small genus of about nine species (The Plant List, 2018). Formerly placed in the Cornaceae and Aucubaceae families, the genus now resides in the Garryaceae (Stevens, 2018). Although currently extant in Eastern Asia (ranging from the Eastern Himalayas east to China, Korea, and Japan and south to Myanmar, Taiwan, and Vietnam), fossil leaves of aucuba from the Eocene have been found in Washington State, suggesting a

Received for publication 16 May 2018. Accepted for publication 6 July 2018 .

This work was funded, in part, by the North Carolina Agricultural Research Service (NCARS), Raleigh, NC, the North Carolina Biotechnology Center, Research Triangle Park, NC, and the Kenan Institute, Raleigh, NC.

Plant material was graciously provided by the JC Raulston Arboretum, Raleigh, NC, the U.S. National Arboretum, Washington, DC, and Dan Hinkley, Indianola, WA. We would like to thank the staff at the Mountain Crop Improvement Lab and Mountain Horticultural Crops Research and Extension Center for their technical assistance.

${ }^{1} \mathrm{JC}$ Raulston Distinguished Professor.

${ }^{2}$ Research intern.

${ }^{3}$ Research specialist.

${ }^{4}$ Director, JC Raulston Arboretum.

${ }^{5}$ Corresponding author. E-mail: tom_ranney@ ncsu.edu. much broader past distribution (Wehr and Hopkins, 1994).

Cultivated for centuries, aucuba are revered as showy, adaptable, evergreen shrubs (Creech, 1984). Aucuba japonica is commonly grown around shrines and temples in Japan, thriving in the understory of Cryptomeria japonica. John Graeffer is credited with introducing $A$. japonica to the Western World in 1783, where it has become an important and valuable landscape plant (The particular merit are many cultivars that have showy, variegated foliage ranging from gold flecking and spots to variegated leaf margins. Although the flowers are inconspicuous and dioecious, female plants can have outstanding displays of red fleshy fruit. In addition to ornamental merit, A. japonica are notoriously tolerant of dry shade, pruning, pollution, and general neglect (Lehrer, 2009). Large specimens frequently are found on old estates and homesteads in the Southeastern United States, where they have long outlived their original gardeners.

Knowledge of ploidy is important for plant breeders, as it can influence crossability, fertility of progeny, segregation of traits, and gene expression. There is limited information on the cytogenetics of aucuba. Some species, including A. chinensis, International Dendrology Society, 2018). Of eriobotryifolia, himalaica, and omeiensis, have been reported to be diploid with $2 n=$ $2 x=16$ (Hara, 1966; Kurosawa, 1971; 1981; The Chromosome Counts Database, 2018). Aucuba japonica are more variable and well-studied, with three varieties ( $j a$ ponica, borealis, and ovoidea) that have been classified based on a combination of morphology, ploidy, and geographic distribution (Ohi et al., 2003). Variety borealis is the most northerly distributed and found in southwestern Hokkaido and the Sea of Japan (Western) side of Honshu and is tetraploid $(2 n=4 x=32)$. Variety japonica is present on the Pacific Ocean (Eastern) side of Honshu and Shikoku and is also tetraploid. Variety ovoidea is distributed further south, ranging from southern Honshu, western Shikoku, and Kyushu to Okinawa, and is diploid. Variety borealis is considered to be the most coldhardy of the group with a smaller stature, decumbent shoots, smaller leaves, and pubescent young buds and inflorescences. Varieties japonica and ovoidea are larger growing and more similar to one another in appearance but clearly differentiated by ploidy. Karyomorpholological studies on a diverse sampling of diploid $A$. japonica var. ovoidea showed the presence of XY sex chromosomes where the fourth-longest pair of chromosomes was heterogeneous in male individuals and homogeneous in female individuals (Tsusaka et al., 2007). Despite the work that has been completed on chromosome numbers and ploidy in aucuba, there is extremely little documentation of ploidy for specific cultivars and clones.

Minimal work has been published on genetics and heritability of specific traits in aucuba. Hagedoorn (1950) first reported that the spotted leaf trait was maternally inherited and that all seedlings from spotted-leaved females had spotted leaves regardless of the male parent and that seedlings from greenleaved female parents always had green leaves even when the pollen parent had spotted leaves. Allen (1990) further substantiated this observation by collecting seed from green-leaved and spotted-leaved plants that all produced seedlings with the same phenotype as the female parent.

There is considerable potential to breed and improve aucuba as nursery crops. The diversity in desirable foliage characteristics (leaf size and variegations), plant size, cold hardiness, and potentially disease resistance and regional adaptability provides substantial opportunities to combine desirable traits. Additional cytogenetic data, with specific information on ploidy of specific cultivars and clones, and information on the mode of inheritance of specific traits, would provide valuable information to better enable plant breeding programs. The objectives of this study were to determine ploidy and relative genome size for a diverse collection of species and cultivars of aucuba using flow cytometry and cytology and to make 
additional observations on the heritability of spotted leaf variegation of specific cultivars.

\section{Materials and Methods}

Plant material. Plants and/or tissue from 57 taxa of aucuba were obtained from the JC Raulston Arboretum (JCRA), Raleigh, NC; the Mountain Crop Improvement Laboratory, Mills River, NC; and the United States National Arboretum, Washington, DC. Current nomenclature for aucuba was adopted from The Plant List (2018) and Xiang and Boufford (2005). Synonyms from accession records and collection data were included when present.

Cytology. Chromosome counts were determined for three taxa, including $A$. chinensis (A. omeiensis, JCRA 120820), A. japonica 'Rozannie' (MCIL 2015-077), and $A$. 'Hosoba' (JCRA 120812) to determine chromosome numbers and calibrate genome size measurements with ploidy. Actively growing root tips were harvested from containergrown plants in mid-July and placed into a solution of $2 \mathrm{~mm} 8$-hydroxyquinoline and $0.248 \mathrm{~mm}$ cycloheximide and incubated for $3 \mathrm{~h}$ at $23{ }^{\circ} \mathrm{C}$, then moved to $4{ }^{\circ} \mathrm{C}$ for an additional $3 \mathrm{~h}$. Roots were then rinsed in cold distilled water and fixed in Carnoy's solution (six parts 95\% ethanol: three parts chloroform: one part glacier acetic acid) at $21{ }^{\circ} \mathrm{C}$ for 18 hours before storage in $70 \%$ ethanol. Fixed roots were hydrolyzed in a $3: 195 \%$ ethanol:12 $\mathrm{M} \mathrm{HCl}$ for $\approx 15 \mathrm{~min}$ and stained with a modified carbol fuchsin stain for at least 5 min (Kao, 1975; Singh, 2003). Root tips were then placed onto a microscope slide with a drop of stain, overlaid with a cover slip. Tissue was squashed underneath a cover slip, and chromosomes were counted at $\times 1000$ magnification.

Flow cytometry. Tissue from vegetative buds $\left(\approx 0.3 \mathrm{~cm}^{2}\right)$ was collected and placed in a plastic petri dish with $\approx 0.3 \mathrm{~cm}^{2}$ of expanding leaf tissue from Pisum sativum 'Ctirad' that served as an internal standard with a known genome size of $2 \mathrm{C}=8.75 \mathrm{pg}$ (Greilhuber et al., 2007). Samples were finely chopped with a razor blade in $0.4 \mathrm{~mL}$ of nuclei extraction buffer (CyStain ultraviolet Precise P Nuclei Extraction Buffer; Sysmex Partec, Görlitz, Germany) and filtered through a $50-\mu \mathrm{m}$ nylon mesh filter. Nuclei were stained with $1.6 \mathrm{~mL} \mathrm{4}{ }^{\prime}$,6-diamidino-2phenylindole (DAPI) before analysis with a flow cytometer (Partec PA II, Munster, Germany). Samples were run until at least 5000 nuclei were counted, and two subsamples were analyzed for each accession. Genome size (2C) of samples was calculated as: $2 \mathrm{C}=$ genome size of standard $\times($ mean fluorescence value of sample $\div$ mean florescence value of standard). The $1 C_{X}$ monoploid genome size (i.e., DNA content of one base set of chromosomes) was calculated as the $2 \mathrm{C}$ genome size $\div$ ploidy level and subjected to analysis of variance by taxa, and means were separated using $\mathrm{LSD}_{0.05}$ (Proc GLM; SAS Version 9.3; SAS Institute, Cary, NC).
Heritability of spotted variegation. Cross pollinations were completed between the female, green-leaved cultivar $A$. japonica 'Petite Jade' and the male, spotted-leaved cultivar A. japonica 'Shilpot' in Mar. 2015. Fruit were collected in the Fall of 2015, seeds were extracted, given cold/moist stratification for $90 \mathrm{~d}$ at $6{ }^{\circ} \mathrm{C}$, and germinated and grown under standard production practices. Seedlings were evaluated for expression of spotted variegations in May 2018.

\section{Results and Discussion}

The chromosome count for $A$. chinensis (A. omeiensis, JCRA 120820) was diploid with $2 n=2 x=16$ (Fig. 1), consistent with a previous report for $A$. chinensis (Kurosawa, 1981). Aucuba japonica 'Rozannie' (MCIL 2015-077) was confirmed to be tetraploid with $2 n=4 x=32$ (Fig. 1), consistent with other reports of tetraploid forms of $A$. japonica var. japonica and var. borealis (Ohi et al., 2003). Surprisingly, A. 'Hosoba' (JCRA 120812) was found to be hexaploid with $2 n=6 x=48$ (Fig. 1), being the first report of a hexaploid aucuba. The species designation of this cultivar has not been determined yet, though records at the JCRA indicate it was of Chinese origin. Confirmation of these cytotypes also provides calibration points to allow estimation of ploidy of other taxa from genome size data.

Relative $2 \mathrm{C}$ genome size for the 57 taxa varied from $13.8 \mathrm{pg}$ for $A$. obcordata to 42.0 pg for $A$. 'Hosoba' (Table 1). These values fell within three discrete groups consistent with cytotype. Genome size for diploid taxa ranged from 13.8 to $21.0 \mathrm{pg}$, tetraploids ranged from 28.8 to $31.2 \mathrm{pg}$, and hexaploids ranged from 40.5 to $42.0 \mathrm{pg}$. These values substantiate previous reports that $A$. chinensis and himalaica are diploid and that A. japonica (including $A$. japonica var. borealis) are tetraploid. The lack of any diploid $A$. japonica var. ovoidea present in our sampling may reflect their more southern nativity and possibly limited cold hardiness restricting their cultivation. Our finding that A. obcordata is diploid is newly reported. In addition to the cytological confirmation that Aucuba 'Hosoba' is hexaploid, genome size measurements indicate that the two Aucuba accessions from Vietnam (JCRA 150090 and 150090) are also hexaploid; however, it would be desirable to confirm this with actual chromosome counts. Although the correct species designations for these Vietnam taxa have not yet been determined, both were wild-collected from Fansipan (Phan Xi Păng) Mountain in North Vietnam at elevations between 2096 and $2310 \mathrm{~m}$.

Overall, these genome size values were similar but greater than those values reported by Zonneveld et al. (2005) for (tetraploid) $A$. japonica, which ranged from 24.9 to $25.7 \mathrm{pg}$ [determined with propidium iodide (PI) stain and Agave americana as an internal standard]. Different fluorochrome stains can give different estimates of absolute genome size, although both PI and DAPI have been found

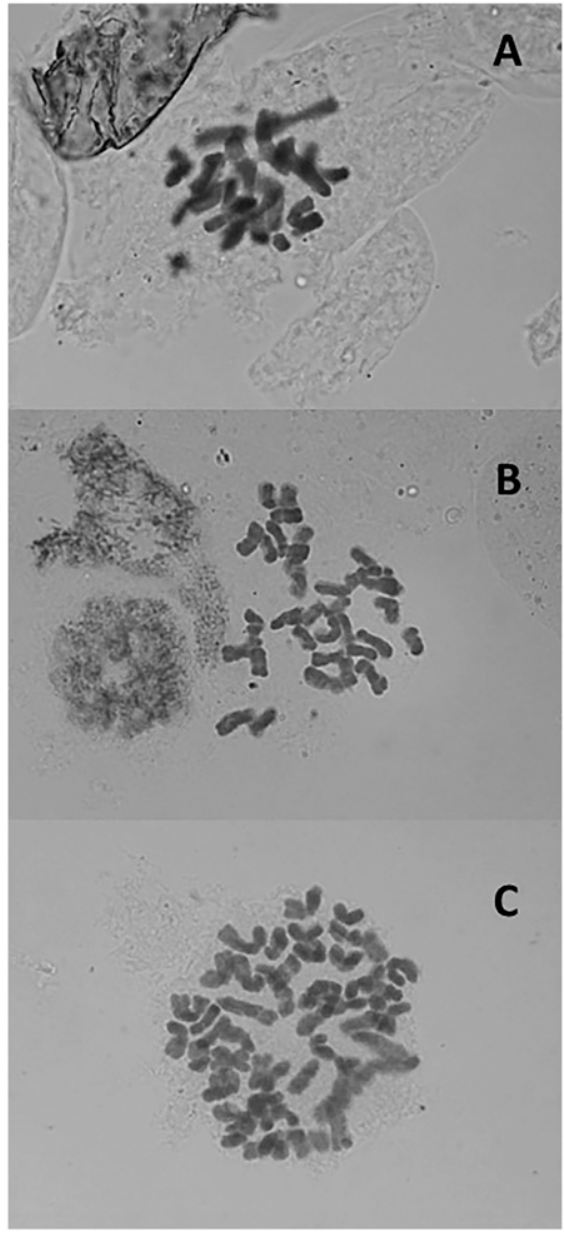

Fig. 1. Somatic chromosomes of (A) Aucuba chinensis $(2 n=2 x=16)$, (B) A. japonica 'Rozannie' $(2 n=4 x=32)$, and (C) $A$. $s p$. 'Hosoba' $(2 n=6 x=48)$.

to be effective and consistent for determining and comparing relative genome size and ploidy among closely related taxa (Parris et al., 2010). Furthermore, DAPI is less expensive, faster, and typically provides more precise and repeatable results as it is specific to double-stranded DNA and is not influenced by variable chromatin structure (Doležel and Bartoš, 2005; Greilhuber et al., 2007).

Base $1 C_{X}$ genome size was fairly similar for most aucuba species, ranging from 6.8 to $7.5 \mathrm{pg}$ with the notable outlier of $A$. chinensis (A. omiensis, JCRA 120820) that had a considerably higher value of $10.6 \mathrm{pg}$. Xiang and Boufford (2005) currently treat $A$. chinensis subsp. omeiensis and A. omeiensis as synonyms for $A$. chinensis. However, the larger and unique base genome size of $A$. chinensis (A. omiensis, JCRA 120820) indicates that this accession/taxon has undergone considerably more within-ploidy genome expansion than other taxa evaluated and may warrant additional study and treatment as a separate species apart from $A$. chinensis.

Cross pollinations of $A$. japonica 'Petite Jade' by $A$. japonica 'Shilpot' yielded 14 seedlings that segregated with three plants 


\begin{tabular}{|c|c|c|c|c|c|}
\hline Taxon & Source ${ }^{\mathrm{z}}$ & Accession & $\begin{array}{l}\text { Relative } 2 \mathrm{C} \\
\text { genome size } \\
(\mathrm{pg}) \pm \mathrm{SEM}\end{array}$ & $\begin{array}{l}\text { Estimated } \\
\text { Ploidy }(x)^{\mathrm{y}}\end{array}$ & $\begin{array}{c}\text { Relative } 1 C_{x} \\
\text { genome size } \\
(p g) \pm \text { SEM } \\
\text { by species }\end{array}$ \\
\hline A. chinensis & JCRA & 090886 & $14.73 \pm 0.04$ & 2 & $7.37 \pm 0.00 \mathrm{BC}$ \\
\hline A. chinensis (A. omeiensis) & JCRA & 120820 & $21.20 \pm 0.14$ & $2 *$ & $10.60 \pm 0.00 \mathrm{D}$ \\
\hline A. himalaica var. oblanceolata (A. japonica f. longifolia) & JCRA & 140141 & $28.70 \pm 0.50$ & 4 & $7.19 \pm 0.10 \mathrm{BC}$ \\
\hline A. himalaica var. oblanceolata 'Salicifolia' (A. japonica f. longifolia 'Salicifolia') & JCRA & 130580 & $28.78 \pm 0.02$ & 4 & \\
\hline A. japonica 'Big Mamma' & JCRA & 110779 & $29.49 \pm 0.04$ & 4 & $7.36 \pm 0.02 \mathrm{BC}$ \\
\hline A. japonica 'Cecil-Alice' & JCRA & 031019 & $29.44 \pm 0.14$ & 4 & \\
\hline A. japonica 'Cho Dai Ji' & JCRA & 100377 & $29.24 \pm 0.61$ & 4 & \\
\hline A. japonica 'Crotonifolia' & JCRA & 011565 & $28.80 \pm 0.04$ & 4 & \\
\hline A. japonica 'Daisuke's Tiger' & JCRA & 120384 & $29.44 \pm 0.01$ & 4 & \\
\hline A. japonica 'Eclipse' & JCRA & 120706 & $29.46 \pm 0.13$ & 4 & \\
\hline A. japonica 'Emily Rose' & MCIL & 2015-079 & $29.83 \pm 0.15$ & 4 & \\
\hline A. japonica 'Fructu Albo' & JCRA & $\mathrm{xx} 0160$ & $28.48 \pm 0.00$ & 4 & \\
\hline A. japonica 'Fujikawa' & JCRA & 100401 & $29.63 \pm 0.16$ & 4 & \\
\hline A. japonica 'Goldilocks' & JCRA & 041654 & $29.30 \pm 0.04$ & 4 & \\
\hline A. japonica 'Hime Kikufurin' & JCRA & 110300 & $28.47 \pm 0.17$ & 4 & \\
\hline A. japonica 'Hosoba Hoshifu' & JCRA & 100347 & $29.98 \pm 0.08$ & 4 & \\
\hline A. japonica 'Kameba' & JCRA & 120385 & $30.59 \pm 0.14$ & 4 & \\
\hline A. japonica 'Koba-no-aoki-fuiki' & JCRA & 140005 & $28.35 \pm 0.35$ & 4 & \\
\hline A. japonica 'Linda Eggins' & JCRA & 130661 & $29.40 \pm 0.57$ & 4 & \\
\hline A. japonica 'Little Angel' & JCRA & 120338 & $29.00 \pm 0.03$ & 4 & \\
\hline A. japonica 'Marmorata' & MCIL & $2015-045$ & $28.89 \pm 0.12$ & 4 & \\
\hline A. japonica 'Meigetsu' & JCRA & 031020 & $29.26 \pm 0.13$ & 4 & \\
\hline A. japonica 'Mr. Goldstrike' & MCIL & $2015-046$ & $29.38 \pm 0.05$ & 4 & \\
\hline A. japonica 'Natsu-no-kumo' & JCRA & 110303 & $29.82 \pm 0.02$ & 4 & \\
\hline A. japonica 'Pacman' & JCRA & 120678 & $29.91 \pm 0.32$ & 4 & \\
\hline A. japonica 'Peachie' & JCRA & 130131 & $29.20 \pm 0.02$ & 4 & \\
\hline A. japonica 'Petite Jade' & JCRA & 140140 & $29.22 \pm 0.27$ & 4 & \\
\hline A. japonica 'Rozannie' & MCIL & 2015-077 & $29.09 \pm 0.12$ & $4 *$ & \\
\hline A. japonica 'Shilpot' Pepperpot ${ }^{\mathrm{TM}}$ & MCIL & 2015-042 & $28.98 \pm 0.21$ & 4 & \\
\hline A. japonica 'Shuugetsu' & JCRA & 110313 & $28.78 \pm 0.06$ & 4 & \\
\hline A. japonica 'Subaru' & JCRA & 110305 & $28.88 \pm 0.18$ & 4 & \\
\hline A. japonica 'Sulphurea Marginata' & JCRA & $\mathrm{xx} 0159$ & $29.49 \pm 0.16$ & 4 & \\
\hline A. japonica 'Suruga Benten' & JCRA & 110307 & $29.45 \pm 0.02$ & 4 & \\
\hline A. japonica 'Tatsumaki' & JCRA & 110301 & $29.71 \pm 0.00$ & 4 & \\
\hline A. japonica (chicory form) & JCRA & 111032 & $29.30 \pm 0.14$ & 4 & \\
\hline A. japonica (cream-white, contorted) & JCRA & 110318 & $30.81 \pm 0.23$ & 4 & \\
\hline A. japonica (gold with green center) & JCRA & 131402 & $28.67 \pm 0.88$ & 4 & \\
\hline A. japonica (dwarf) & JCRA & 120704 & $30.64 \pm 0.26$ & 4 & \\
\hline A. japonica (seedling \#6) & JCRA & 041598 & $30.26 \pm 0.23$ & 4 & \\
\hline A. japonica (thin white margin) & JCRA & 110306 & $29.68 \pm 0.19$ & 4 & \\
\hline A. japonica (USNA \#3 - female) & JCRA & 040065 & $29.99 \pm 0.45$ & 4 & \\
\hline A. japonica (USNA \#4) & JCRA & 040066 & $29.30 \pm 0.44$ & 4 & \\
\hline A. japonica (USNA \#5 - female) & JCRA & 040067 & $30.02 \pm 0.15$ & 4 & \\
\hline A. japonica & USNA & 2016-034 & $30.52 \pm 0.19$ & 4 & \\
\hline A. japonica var. borealis 'Bored Female' & MCIL & $2015-043$ & $29.65 \pm 0.20$ & 4 & $7.53 \pm 0.07 \mathrm{C}$ \\
\hline A. japonica var. borealis 'Honshu' & JCRA & 140004 & $29.23 \pm 0.18$ & 4 & \\
\hline A. japonica var. borealis 'Sea of Japan' & MCIL & 2015-067 & $28.78 \pm 0.01$ & 4 & \\
\hline A. japonica var. borealis & USNA & 2016-035 & $31.22 \pm 0.46$ & 4 & \\
\hline A. japonica var. borealis & USNA & 2016-036 & $30.54 \pm 0.35$ & 4 & \\
\hline A. japonica var. borealis & USNA & 2016-037 & $30.61 \pm 0.07$ & 4 & \\
\hline A. japonica var. borealis & USNA & 2016-038 & $30.34 \pm 0.00$ & 4 & \\
\hline A. japonica var. borealis & USNA & 2016-039 & $30.49 \pm 0.41$ & 4 & \\
\hline A. obcordata & JCRA & 121186 & $13.84 \pm 0.00$ & 2 & $7.02 \pm 0.10 \mathrm{AB}$ \\
\hline A. aff. obcordata & JCRA & 140899 & $14.23 \pm 0.08$ & 2 & \\
\hline A. sp. (Vietnam, female - Hinkley, DJHV 8035) & JCRA & 150091 & $40.46 \pm 0.06$ & 6 & $6.76 \pm 0.02 \mathrm{~A}$ \\
\hline A. sp. (Vietnam, male - Hinkley and Wynn Jones, HWJ 1006) & JCRA & 150090 & $40.67 \pm 0.16$ & 6 & \\
\hline A. sp. 'Hosoba' & JCRA & 120812 & $42.01 \pm 0.00$ & $6 *$ & $7.00 \pm 0.00 \mathrm{AB}$ \\
\hline
\end{tabular}

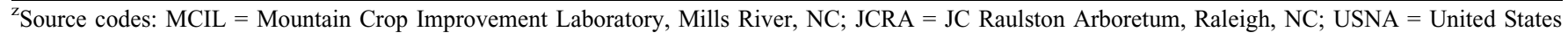
National Arboretum, Washington, DC.

${ }^{\mathrm{y}}$ Values followed by an asterisk were confirmed with cytology.

${ }^{\mathrm{x}}$ Values followed by different letters within a column are significantly different, least significant difference, $P \leq 0.05$.

with homogeneous green leaves, three plants with faint and infrequent spots, and eight plants moderate-to-heavy variegation (Fig. 2). Considering that these plants are tetraploids, the population size was not large enough to adequately categorize the phenotypes and model the exact mode of inheritance, but it is clear that the spotted variegation trait of
'Shilpot' is quantitative and not strictly maternally inherited. This result is inconsistent with previous reports that the mode of inheritance in aucuba is strictly maternal/ extranuclear (Allen, 1990; Hagedoorn, 1950). Although these earlier reports did not identify the particular clones used in their crosses, our combined results indicate that there are probably multiple genes with different modes of inheritance that can give rise to variegated aucuba plants. The spotted-leaved trait expressed in A. japonica 'Shilpot' is most likely a nuclear gene with multiple alleles and quantitative inheritance. Alternatively, if it is an extranuclear gene, it would have to be inherited 


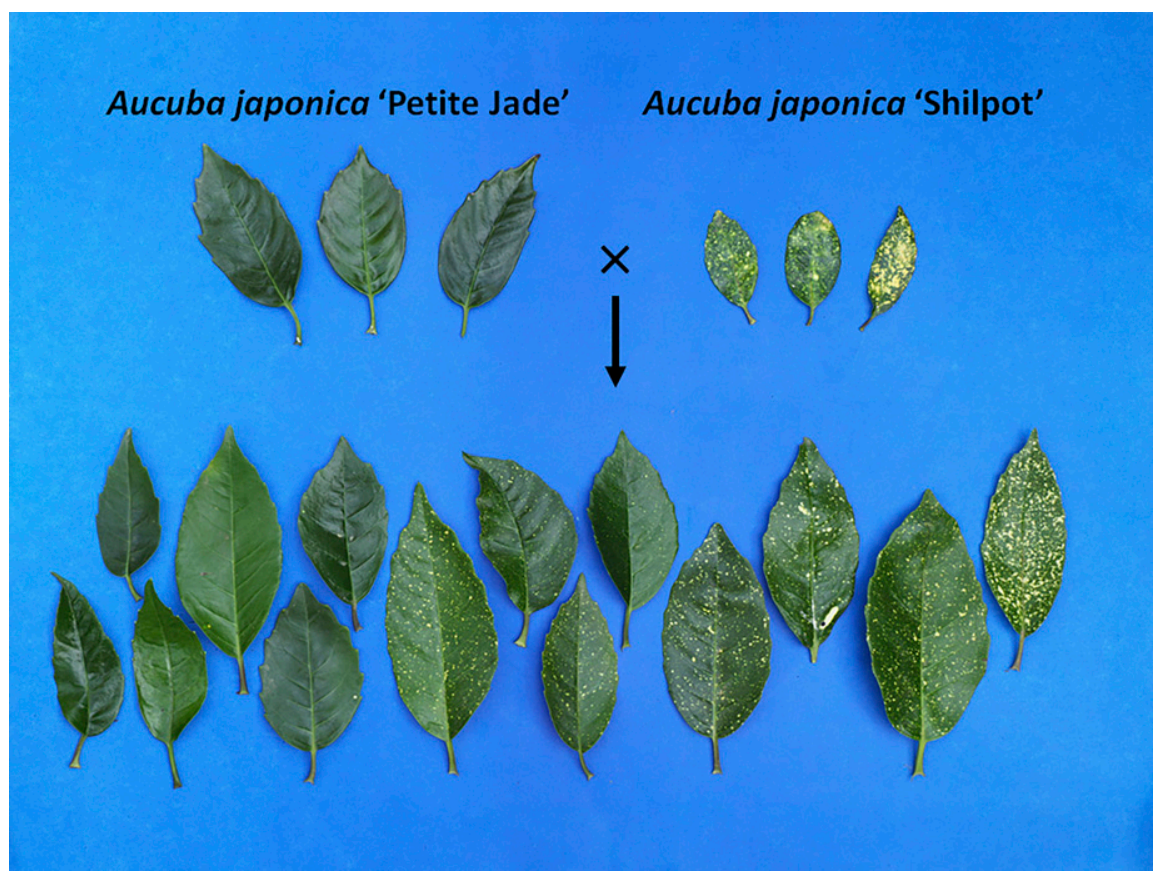

Fig. 2. Representative leaves from parents and $14 \mathrm{~F}_{1}$ hybrids between Aucuba japonica 'Petite Jade' (female) and $A . j$. 'Shilpot' (male).

paternally/biparentally. Additional observations of seedlings from open-pollinated, green-leaved plants of $A$. japonica var. borealis 'Honshu' also produced seedlings with spotted leaves (data not presented), further corroborating that spotted variegation is not always maternally inherited.

These results document relative genome size and ploidy of a diverse collection of aucuba species and cultivars including cultivated and wild-collected specimens. Additional data are presented on a newly described quantitative mode of inheritance for a desirable spotted variegation trait. These data provide basic information on cytogenetics and heritability for specific clones and cultivars to aid in future breeding and improvement of aucuba. Expanded sampling of species and unclassified taxa has shown a wider range of ploidy and base genome size than previously
Hara, H. 1966. Taxonomic comparison between corresponding taxa of Spermatophyta in Eastern Himalaya and Japan, p. 627-657. In: H. Hara (ed.). The flora of eastern Himalaya. University of Tokyo, Tokyo, Jpn.

Kao, K.N. 1975. A nuclear staining method for plant protoplasts, p. 60-62. In: O.L. Gamborg and L.R. Wetter (eds.). Plant tissue culture methods. Natl. Res. Council Canada Prairie Reg. Lab., Saskatoon, Saskatchewan.

Kurosawa, S. 1971. Cytotaxonomical studies on the genus Aucuba. Shokubutsu Kenkyu Zasshi 46:231-238.

Kurosawa, S. 1981. Notes on chromosome numbers of Spermatophytes (3). Shokubutsu Kenkyu Zasshi 56:245-251.

Lehrer, J.M. 2009. Shedding new light on Aucuba. Amer. Nurseryman. Sept. 38-43.

Ohi, T., T. Kajita, and J. Murata. 2003. Distinct geographic structure as evidenced by chloroplast DNA haplotypes and ploidy level in Japanese Aucuba. Amer. J. Bot. 90(11):16451652.

Parris, J.K., T.G. Ranney, H.T. Knap, and W.V. Baird. 2010. Ploidy levels, relative genome size, and base pair composition in magnolia. J. Amer. Soc. Hort. Sci. 135(6):533-547.

Singh, R.J. 2003. The handling of plant chromosomes, p. 9-11. In: Plant cytogenetics. 2nd ed. CRC Press LLC, Boca Raton, FL.

Stevens, P.F. 2018. Angiosperm phylogeny website. 3 May 2018. <http://www.mobot.org/ MOBOT/research/APweb/>.

reported that provides additional insights into the evolution and systematics of this genus.

\section{Literature Cited}

Allen, E.F. 1990. Aucuba japonica an example of cytoplasmic inheritance. Plantsman (Lond., Engl.) 11(4):244-245.

Creech, J.L. 1984. Aucuba japonica is a colorful broad-leaved evergreen. Amer. Nurseryman. Jan. 47-48.

Doležel, J. and J. Bartoš. 2005. Plant DNA flow cytometry and estimation of nuclear genome size. Ann. Bot. 95:99-100.

Greilhuber, J., E.M. Temsch, and J.C.M. Loureiro. 2007. Nuclear DNA content measurement, $\mathrm{p}$ 67-101. In: J. Doležel, J. Greilhuber, and J. Suda (eds.). Flow cytometry with plant cells: Analysis of genes, chromosomes and genomes. Wiley-VCH, Weinheim, Germany.

Hagedoorn, A.L. 1950. Plant breeding. Crosby Lockwood, London.
The Chromosome Counts Database. 2018. Aucuba. 3 May 2018. $<$ http://ccdb.tau.ac.il/>.

The International Dendrology Society. 2018. Trees and shrubs online. $<$ http://treesandshrubsonline. org/>.

The Plant List. 2018. Version 1.1. 27 Apr. 2018. $<$ http://www.theplantlist.org/>. karyomorphological study of diploid races of Aucuba japonica Thunb. (cornaceae) in southern Japan, to confirm the presence of sex chromosomes. J. Jap. Bot. 82:126-129.

Wehr, W.C. and D.Q. Hopkins. 1994. The Eocene orchards and gardens of Republic. Washington. Washington Geol. 22:27-34.

Xiang, J.Q. and D.E. Boufford. 2005. Aucubacea. Flora China 14:222-226.

Zonneveld, B.J.M., I.J. Leitch, and M.D. Bennett. 2005. First nuclear DNA amounts in more than 300 angiosperms. Ann. Bot. 96:229244.
Tsusaka, M., H. Ikeda, and T. Hoshino. 2007. A 